Neurosurg Focus 5 (3):Article 9, 1998

\title{
Hemorrhagic vestibular schwannoma: an unusual clinical entity
}

\section{Case report}

Dean Chou, M.D., Prakash Sampath, M.D., and Henry Brem, M.D.

Departments of Neurological Surgery and Neuro-Oncology, The Johns Hopkins Hospital, Baltimore, Maryland

Hemorrhagic vestibular schwannomas are rare entities, with only a few case reports in the literature during the last 25 years. The authors review the literature on vestibular schwannoma hemorrhage and the presenting symptoms of this entity, which include headache, nausea, vomiting, sudden cranial nerve dysfunction, and ataxia. A very unusual case is presented of a 36-year-old man, who unlike most of the patients reported in the literature, had clinically silent vestibular schwannoma hemorrhage. The authors also discuss the management issues involved in more than 1000 vestibular schwannomas treated at their institution during a 25-year period.

Key Words * acoustic tumor * schwannoma * neuroma * hemorrhage * hemorrhagic vestibular tumor

Vestibular schwannomas are the most common tumors found in the cerebellopontine angle (CPA), comprising approximately $80 \%$ of all tumors arising in this region. They are usually slow-growing, benign tumors that manifest clinically by directly compressing the neural elements traversing the CPA, including the pons, cerebellum, and the lower cranial nerves. Hemorrhage into a vestibular schwannoma is rare and has been shown to present with acute neurological changes and deterioration. We review the literature on the presenting symptoms of hemorrhagic vestibular schwannomas and describe the case of a man with a large hemorrhagic vestibular schwannoma who presented with signs and symptoms of a slow-growing, insidious compressive lesion. In doing so, we hope to shed light on this unusual clinical entity and discuss management issues.

\section{CASE REPORT}

This 36-year-old man had a 6-month history of gradual hearing loss in his left ear. He noted intermittent tinnitus in his left ear and mild intermittent left-sided headaches. His physical examination was otherwise normal. His medical history was significant only for his taking aspirin for pain. Audiography was performed that demonstrated decreased hearing on his left side. A gadolinium-enhanced magnetic resonance (MR) image demonstrated a 2 X 2 X 2-cm peripherally enhancing mass in the left CPA (Fig. 
1) with a fluid-filled central cavity consistent with a hematoma. The mass extended into the petrous apex, the pons, and the cerebellar peduncle; it slightly indented the brainstem, but caused no hydrocephalus.

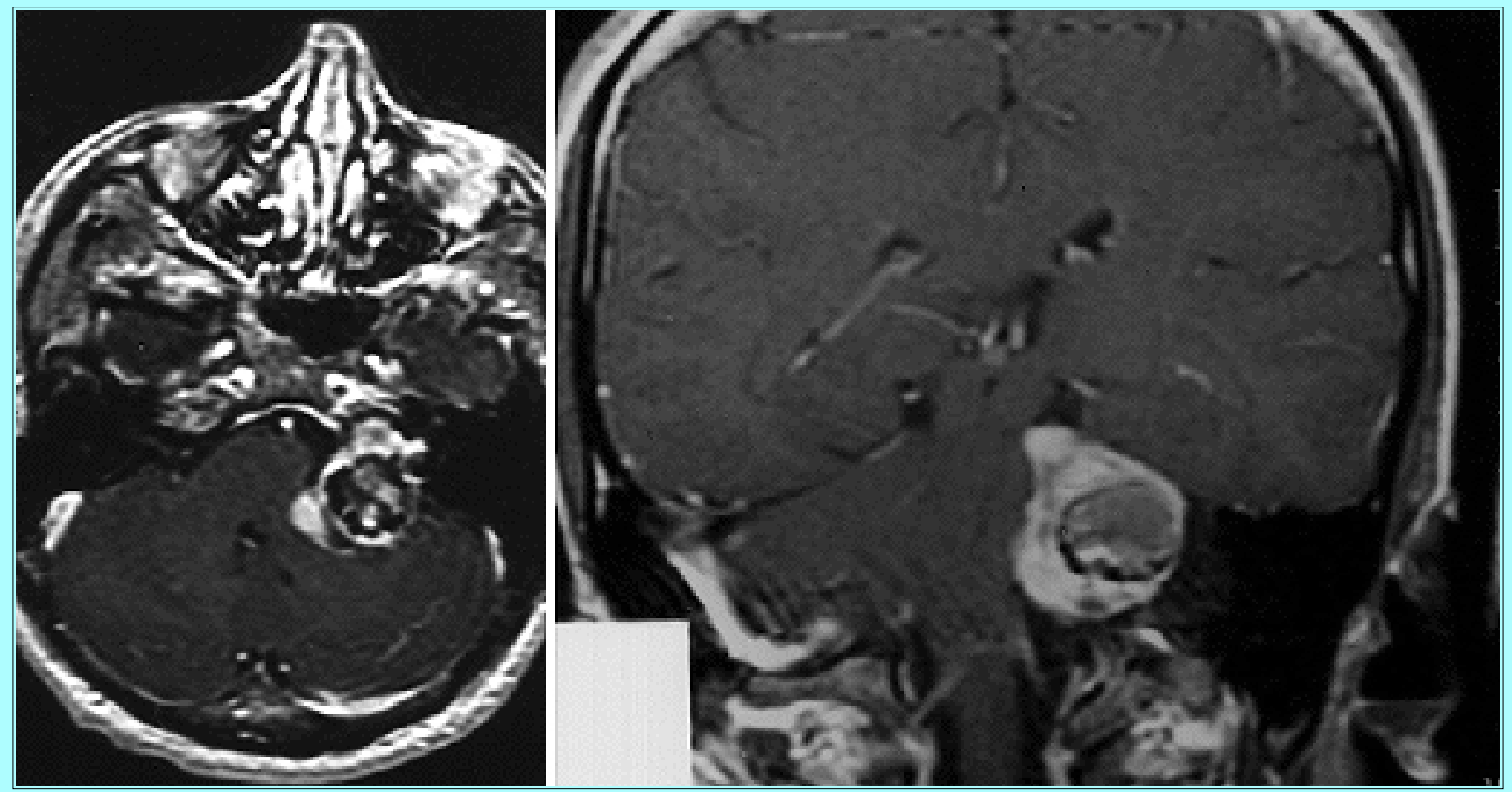

Fig. 1. Magnetic resonance images, axial and coronal views, after administration of contrast material, showing a vestibular schwannoma with intratumoral hemorrhage.

The patient underwent a left suboccipital craniectomy for resection of tumor performed by the combined services of neurosurgery and otolaryngology. Intraoperatively, the tumor was well encapsulated; it grossly compressed the lower cranial nerves and extended from the porus acusticus. After the tumor capsule was entered, the hematoma that had been visualized on MR imaging was encountered. It had components of organized and liquid clot. It was easily removed and a gross-total resection was achieved. The pathological composition of the lesion was that of a schwannoma with no increased vascularity. The patient did well postoperatively.

\section{DISCUSSION}

Vestibular schwannomas (acoustic neuromas or acoustic schwannomas) are the most common primary tumors arising from the CPA in adults. Patients usually present with hearing loss, tinnitus, dysequilibrium, headache, and facial numbness. Other more rare symptoms may also manifest such as facial weakness, nausea and vomiting, otalgia, and taste abnormalities. The progression of these symptoms is usually slow and insidious, and often patients will not present to medical attention until their tumors have become quite large.[7]

The tumors' appearance on MR studies is slightly hypo-to-isointense to brain on $\mathrm{T}_{1}$-weighted imaging and the signal intensity is decreased on $\mathrm{T}_{2}$-weighted imaging. Almost all schwannomas will enhance after gadolinium administration, and the enhancement is homogeneous in $67 \%$ of them. There is noted cystic degeneration, but hemorrhage into the lesion is not common.[4,10,12]

Most series have shown that hemorrhagic vestibular schwannomas are rare. Wakai, et al.,[16] demonstrated in their series of 1861 brain tumors that the average rate of all brain tumor hemorrhages 
was $5.1 \%$. Their study included 193 vestibular schwannomas, none of which bled. Curati, et al.,[4] also published a series of 35 patients with vestibular schwannomas, and there was no specific mention of hemorrhage in any of them. It appears that the rate of bleeding is low and that most hemorrhagic vestibular schwannomas are presented as case reports.

There is a wide range of presenting symptoms in patients with hemorrhagic vestibular schwannoma, varying from subarachnoid hemorrhage (SAH) symptoms to acute cranial nerve deficits (Table 1).

\section{TABLE 1}

PrESENTNG SVMPTOMS OF PATIENTS WITH HEMORRHAGIC ACOUSTIC SCHWANNOMAS

\begin{tabular}{|c|c|c|c|c|c|}
\hline Authors \& Year & $\begin{array}{l}\text { Age }[(y s), \\
\operatorname{Sex}\end{array}$ & Presenting Symptoms & $\begin{array}{l}\text { Acute } \\
\text { Orset }\end{array}$ & $\mathrm{SAH}$ & $\begin{array}{l}\text { Prior } \\
\text { Irsido us } \\
\text { Orset }\end{array}$ \\
\hline McCoyd, et al., 1974 & $64, F$ & $\begin{array}{l}\text { nausea, womiting, It meakness, } \\
\text { mental status changes }\end{array}$ & Yes & Yes & No \\
\hline She phard \& Cheeks, 1981 & $\begin{array}{l}37, M \\
66, M\end{array}$ & $\begin{array}{l}\text { comatose } \\
\text { deafness, ataxia, sensory } \\
\text { changes, It facial meakness }\end{array}$ & $\begin{array}{l}\text { Yes } \\
\text { Yes }\end{array}$ & $\begin{array}{l}\text { No } \\
\text { Yes }\end{array}$ & $\begin{array}{l}\text { No } \\
\text { Yes }\end{array}$ \\
\hline Castillo, et al., 1982 & $61, M$ & $\begin{array}{l}\text { severe rt ear pain, womiting, } \\
\text { dizziness }\end{array}$ & Yes & Yes & Yes \\
\hline Yonemitsu, et al., 1983 & $49, M$ & $\begin{array}{l}\text { sudden headache, nausea, } \\
\text { womiting }\end{array}$ & Yes & Yes & Yes \\
\hline Goetting \& Swanson, 1987 & $19, \mathrm{M}$ & $\begin{array}{l}\text { It otalgia, 'uertigo, womiting, } \\
\text { sueating, facial meakness }\end{array}$ & Yes & Yes & Yes \\
\hline Lee \& Whang, 1989 & $65, F$ & $\begin{array}{l}\text { severe he adache, wertigo, } \\
\text { womiting }\end{array}$ & Yes & No & Yes \\
\hline Brady \& Stack, 1994 & $70, M$ & $\begin{array}{l}\text { diplopia, nausea, headache, } \\
\text { facial ner we palsy }\end{array}$ & Yes & - & Yes \\
\hline present case & 36 , M & gradual hearing loss & No & No & Yes \\
\hline
\end{tabular}

McCoyd, et al.,[11] reported the case of a woman who had tonsillar herniation secondary to hemorrhagic acoustic neuroma. Castillo, et al.,[3] described a man who had "severe pain in the right ear accompanied by dizziness and several episodes of vomiting" and who also had suffered SAH. Shephard and Cheeks[14] reported on two patients: one presented in a coma with SAH and the other with sudden deafness, ataxia, and sensory changes. Yonemitsu, et al.,[18] Brady and Stack,[2] and Lee and Wang[9] all reported cases of patients who presented with severe headache, nausea, and vomiting. Goetting and Swanson[6] treated a patient who presented with acute left-sided otalgia and facial weakness after engaging in weight lifting. Asari, et al.,[1] presented four patients with hemorrhagic acoustic schwannomas: two had developed acute onset of headache and vomiting. Almost all of the case reports of patients with hemorrhagic vestibular schwannomas describe sudden, acute onset of symptoms, neurological deterioration, or frank SAH.

Although most case reports of patients with hemorrhagic vestibular schwannomas cite sudden onset of symptoms and neurological changes, we present a case that was neither symptomatic nor devastating. Our patient's slow, insidious clinical course was very typical of most vestibular schwannomas, and the hemorrhage was silent. The patient does have a history of taking aspirin, which may have predisposed him to bleed into the tumor. Magnetic resonance imaging indicated that the bleeding may have contributed to the expansion of the tumor. The intraoperative exposure demonstrated that there was liquefied and organized clot, suggesting that there may have been multiple bleeds into the tumor at different times. 
Of more than 1000 patients treated at our institution over a 25-year period, there have been only a handful with hemorrhagic vestibular schwannomas. In contemporary management of vestibular schwannomas, treatment options consist of observation by means of serial imaging, radiosurgery, or microsurgical resection. The observation option may risk rehemorrhage with acute neurological deterioration as described by other authors (Table 1). The role radiosurgery may play in treating hemorrhagic vestibular schwannomas is difficult to predict. Although radiosurgery appears to be effective in treating highly vascular lesions such as hemangioblastomas[13] or arteriovenous malformations, $[15,17]$ its role in the treatment of many other lesions still needs to be defined.[5,8] We advocate surgical resection of these hemorrhagic tumors by means of either a suboccipital or a translabyrinthine approach. It is our belief that microsurgical resection provides the easiest, most direct route to achieve evacuation of the hemorrhagic component of the tumor, which minimizes risks to critical surrounding nerves and dramatically reduces the mass effect.

\section{CONCLUSIONS}

Vestibular schwannomas are the most common primary tumors of the CPA, and they usually present with insidious onset, but without hemorrhage. Almost all cases of patients with hemorrhagic vestibular schwannoma reported in the literature describe sudden, dramatic changes in clinical signs and symptoms. We present a case of a man who appeared to have had multiple bleeds, yet still presented with a slow progressive course. This clinical entity and its management should be of interest to neurosurgeons and neurootologists who may see this unusual presentation.

Click here to view commentary on this article.

\section{References}

1. Asari S, Katayama S, Itoh T, et al: CT and MRI of haemorrhage into intracranial neuromas. Neuroradiology 35:247-250, 1993

2. Brady AP, Stack JP: Case report: magnetic resonance demonstration of haemorrhagic acoustic neuroma. Clin Radiol 49:61-63, 1994

3. Castillo R, Watts C, Pulliam M: Sudden hemorrhage in an acoustic neuroma. Case report. J Neurosurg 56:417-419, 1982

4. Curati WL, Graif M, Kingsley DPE, et al: MRI in acoustic neuroma: a review of 35 patients. Neuroradiology 28:208-214, 1986

5. Duma C, Lunsford LD, Kondziolka D, et al: Stereotactic radiosurgery of cavernous sinus meningiomas as an addition or alternative to microsurgery. Neurosurgery 32:699-705, 1993

6. Goetting MG, Swanson SE: Massive hemorrhage into intracranial neurinomas. Surg Neurol 27168-172, 1987

7. Harner SG, Laws ER Jr: Clinical findings in patients with acoustic neurinoma. Mayo Clin Proc 58:721-728, 1983

8. Kondziolka D, Niranjan A, Lunsford LD: Current status of radiosurgery for meningiomas. Contemp 
Neurosurg 20:1-5, 1998

9. Lee JP, Wang ADJ: Acoustic neurinoma presenting as intratumoral bleeding. Neurosurgery 24:764-768, 1989

10. Lessin BD, Alenghat JP: Magnetic resonance imaging of hemorrhagic acoustic neuroma. Clin Imaging 17:142-145, 1993

11. McCoyd K, Barron KD, Cassidy RJ: Acoustic neurinoma presenting as subarachnoid hemorrhage. Case report. J Neurosurg 41:391-393, 1974

12. Mulkens TH, Parizel PM, Martin JJ, et al: Acoustic schwannoma: MR findings in 84 tumors. AJR 160:395-398, 1993

13. Patrice SJ, Sneed PK, Flickinger JC, et al: Radiosurgery for hemangioblastoma: results of a multiinstitutional experience. Int J Radiat Oncol Biol Phys 35:493-499, 1996

14. Shephard RH, Cheeks RE: Subarachnoid haemorrhage and acoustic neuroma. J Neurol Neurosurg Psychiatry 44:1057, 1981 (Letter)

15. Souhami L, Olivier A, Podgorsak EB, et al: Dynamic stereotactic radiosurgery in arteriovenous malformation. Preliminary treatment results. Cancer 66:15-20, 1990

16. Wakai S, Yamakawa K, Manaka S, et al: Spontaneous intracranial hemorrhage caused by brain tumor: its incidence and clinical significance. Neurosurgery 10:437-444, 1982

17. Yamamoto M, Jimbo M, Kobayashi M, et al: Long-term results of radiosurgery for arteriovenous malformation: neurodiagnostic imaging and histological studies of angiographically confirmed nidus obliteration. Surg Neurol 37:219-230, 1992

18. Yonemitsu T, Niizuma H, Kodama N, et al: Acoustic neurinoma presenting as subarachnoid hemorrhage. Surg Neurol 20:125-130, 1983

Manuscript received August 20, 1998.

Accepted in final form August 28, 1998.

Address reprint requests to: Henry Brem, M.D., The Johns Hopkins Hospital, Hunterian 817, 725 North Wolfe Street, Baltimore, Maryland 21205. 